\title{
Vertical Greening Wall as Sustainable Approach
}

\author{
Ahmad Ridzwan Othman, Norshamira Sahidin \\ Faculty of Architecture, Planning and Surveying, \\ Universiti Teknologi MARA (UiTM), \\ 40000 Shah Alam, Malaysia \\ dwan_arc7@yahoo.com
}

\begin{abstract}
To overcome the excessive heat in tropical climate countries during the day, the types of skin or façade play a vital role in regulating the temperature and the amount of heat transmission in a building. This research was carried out to evaluate the percentage of temperature reduction of two building samples, one with "vertical greening" and one without. The result proved that the temperature reduction of the building with the green façade system is higher than the building without the green façade system. Therefore, it justifies that Vertical Greening Wall does act as an acceptable passive approach for sustainable design.
\end{abstract}

Keywords: Vertical greening; passive approach; facade; sustainable design

eISSN: 2398-4279 ๑ 2016. The Authors. Published for AMER ABRA by e-International Publishing House, Ltd., UK.. This is an open access article under the CC BY-NC-ND license (http://creativecommons.org/licenses/by-ncnd/4.0). Peer-review under responsibility of AMER (Association of Malaysian Environment-Behaviour Researchers), ABRA (Association of Behavioural Researchers on Asians) and $c E-B s$ (Centre for EnvironmentBehaviour Studies), Faculty of Architecture, Planning \& Surveying, Universiti Teknologi MARA, Malaysia.

https://doi.org/10.21834/ajqol.v1i3.22 


\subsection{Introduction}

Green architecture is one of the many ways to reduce the impact of construction of a new building on nature. The term green architecture is not just by preserving and conserving the trees on site but can also be implemented as part of the buildings component. One of the ways to implement nature on architecture is by using the 'breathing walls' on the facade or what we call as vertical greening.

Vertical greening façade is an exterior wall that is planted with plants mainly used for aesthetic and ecological purpose. To create the vertical greening facade, the plant must be of certain characters and the wall or support structure must be occupied with soil and water system. Usually, the plant that is used for the vertical greening facade is aerial roots plant, vines and also climbing plants. The support structure is used for the plant to be able to climb or cascade down the structure.

According to (Sunakorn and Yimprayoon 2011) vertical garden or green façade are also becoming popular landscape design for home and building. It is widely known that plant absorbs heat and light from the sun for photosynthesis process and the best solution to improve the air quality in certain places since it absorbs the carbon dioxide during the day. Based on these criteria, we can conclude that the vertical greening system can reduce the heat and temperature and also improve the air quality in a building.

Lastly, based on the research by the National University of Singapore, the electricity can be reduced by $5 \%$ if the temperature of a building decreased by $1^{\circ} \mathrm{C}$. This strongly supports the evidence before a research by (Sheweka and Mohamed 2012); a vertical greening system can reduce the temperature in a building by two degrees during the day and 0.4 degrees at night.

\subsection{Problem statement}

Most of the electricity is used to provide a thermally and visually comfortable builtenvironment through air-conditioning and artificial lighting. Earlier studies by Goulding et al. (1992) and Krarti (2000), on energy audits and surveys of commercial premises, revealed that air-conditioning and artificial lighting account for, respectively, $40-60 \%$ and $20-30 \%$ of total electricity use. One of the ways to reduce the energy used is through the implementation of the passive design approach. The passive design approach is where the heating and cooling system of the building is provided without any means of mechanical energy use whereas, the bioclimatic design is the application of climate study into the design and building's technology mainly to regulate the heat transfer. Therefore, the combination of these two approaches is essential in promoting an energy-saving building as well as ensuring thermal comfort for the building's occupant.

In designing a building based on the bioclimatic approach, the most important part of the building is the skin or the facade. It acts as the control medium of any forces that passes the building. Therefore, the design of the skin or envelope of an office building plays a vital role in maintaining the thermal comfort of the building's occupant from the climate 
condition. Many projects using the vertical greening system as facade can be seen across the world. However, these designs are not making the full use and benefits of the vertical garden itself. For example in Jakarta, most buildings with vertical garden facade are implemented mainly because of its aesthetic value. This is due to the lack of research concerning the thermal effect of vertical garden and the exact percentage of temperature reduction.

\subsection{Purpose of study}

The aim of this research is to determine the temperature and the humidity in an office building that uses vertical greening system thus proving that this method can be best implemented in tropical climate countries. By observing the temperature differences in both office and the humidity percentage in a building, the effectiveness of vertical greening facade can be obtained. This investigation was done by recording the temperature in both offices (one with vertical greening façade and one not using the vertical greening façade system) from the same location during the day and observing the energy used by both buildings during the working hour period.

\subsection{Aims and objectives of research}

This research was carried to evaluate the percentage of temperature reduction of two building samples, one with "vertical greening" and one without. The aim of the study is to investigate whether there are any differences in temperature and humidity in both office buildings during the day. The objectives of this research are listed below.

- To obtain the temperature and humidity differences in both offices.

- $\quad$ To determine the effectiveness of vertical greening façade system.

\subsection{Literature Review}

\subsection{Thermal comfort}

The essential principle to achieve an adequate environmental condition is by accommodating the building's occupant with a satisfactory thermal condition. According to British Standard BS EN ISO 7730 (2005), thermal comfort is the state where the person's mind is satisfied with the current thermal condition in their surroundings. In short, it is when a person's brain stimulates the feeling of either too hot or too cold.

The term thermal comfort is hard to define since it depends on certain criteria and varies according to the human body. However, the factors affecting thermal comfort in a workplace can be divided into two main categories, environmental factors, and personal factors (McMullan, 1998). 
Environmental factors

- Air temperatures

- Radiant temperatures

- Air velocity

- Humidity
Personal factors

Clothing insulation

Metabolic rate

The environmental factor is where the thermal condition is taken into account during the thermal comfort evaluation. This factor can be obtained using certain apparatus and measurement. However, the personal factors are difficult to measure since the human psychology is different. This claim can be supported by McMullan (1998), whereby, the occupants hardly come to terms that the current internal environment in their offices is good enough.

\subsection{Building characteristics in tropical climate}

According to Nedhal et al. (2013), the tropical climate is considered as one of the most difficult climates being implemented into the design. The high temperature and humidity all year round result in the exceeding temperature of summertime comfort. According to ASHRAE (2013), the indoor temperature that is suitable during summertime to achieve thermal comfort is $26^{\circ} \mathrm{C}$. However, this temperature limit is can no longer be applied in tropical climate countries. To regulate the high temperature and humidity to achieve thermal comfort, there are many strategies that can be taken. For tropical climate, the building design should focus more on controlling the amount of heat transition and ventilations. In short, it is where the heat in a building is rejected while the light and cool air is admitted.

Based on the research conducted in Penang, Malaysia by Syed Fadzil et al. (2004), the orientation of the building in tropical climate with the lowest amount of sun penetrates into the building is at the bay with orientation of $0^{\circ}$ whereas, the highest amount of sunlight that enters the building is at the bay of orientation of $240^{\circ}$. The orientation of the building is important to reduce the temperature of a building and to save energy used to maintain thermal comfort. Approximately $43 \%$ of energy can be reduced if the building is designed in the right orientation. The openings in a tropical climate building should be as large as possible to allow the cross-ventilation to occur.

\subsubsection{Vertical greening wall}

The living walls consist of more than one type of plants. Using this method, groundcover plants are made possible to be planted vertically on the wall surface. It is made up of planted or vegetated modular structures that are of plastics, metal, or other materials that are connected vertically to a structural frame. This type of the vertical garden usually needs 
more maintenance compared to another system since it has to support a great range of plant species. The system of living walls is different according to the design and functions.

\subsubsection{Modular living walls (green screen)}

A modular living wall is inspired by the system of a green roof that uses modules as a medium to support the growth of plants. In this system, the plant is supported by multiples panels that are of square and rectangular shapes. Each panel consists of growing medium that contains different soil and nutrients composition depending on the types of plant used. The irrigation for this system is usually placed on top of the modules to distribute the water through the growing media using gravity pulls.

\section{Vegetated Mat wall}

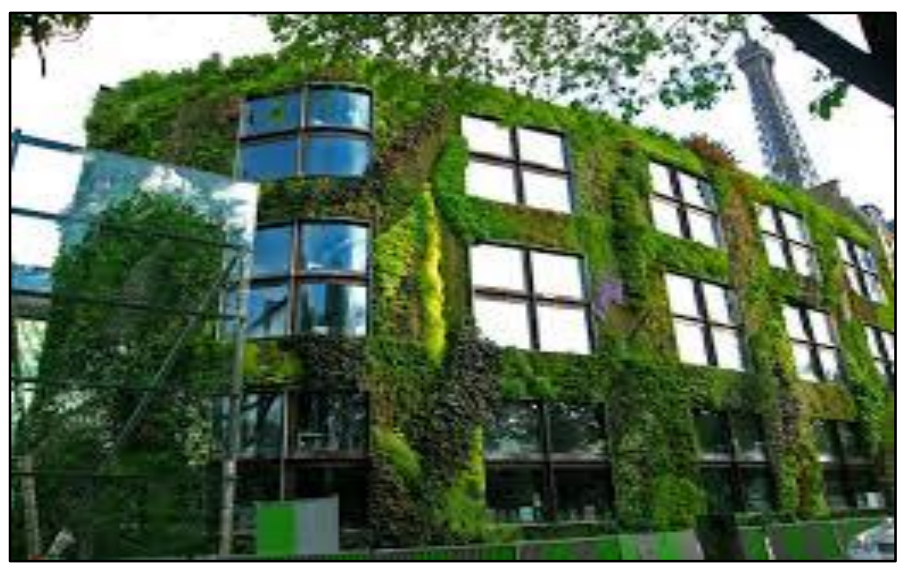

Figure 1: The famous 'Mur Vegetal' by Patrick Blanc

(Source: http://www.murvegetalpatrickblanc.com/patrick-blanc)

The 'Mur Vegetal' is a unique form of green facade system that is engineered by the French botanist, Patrick Blanc. In this system, the plant is supported by two layers of synthetic fabric with pockets. These fabric walls are later connected to a larger frame located on top of the wall surface layered with a waterproof membrane to prevent any damage to the existing wall due to its high moisture content. Similar to the irrigation system of the modular living walls, water and nutrients are distributed evenly ac water and nutrients are distributed evenly across the fabric using the gravity pulls. 


\subsubsection{Bio-filtration}

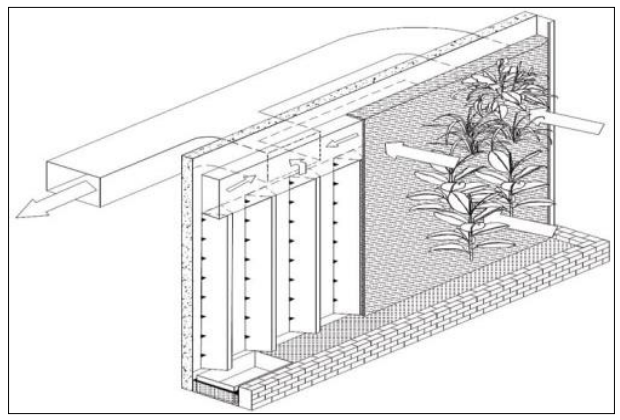

Figure 2: Bio-filtration system

(Source: http://continuingeducation.construction.com)

This type of green facade system fully uses the benefits of the vegetated wall. The basic mechanics of bio-filtration system provides thermal regulation and filters the polluted air outside the building using the fan as the generator mechanism. The irrigation system that provides nutrients and water to the plant is similar to the hydroponic technique of plantation where the water is re-circulated from the nutrients solution tank located on top of the wall system. To support the plant roots and the microbes, two layers of synthetic fabrics are placed on top of the gutter that irrigates the nutrients solution. The function of microbes in the synthetic fabric is to expel the airborne volatile organic compounds (VOC) and hazardous chemical pollutants from the other building materials from entering the building and affect the human health.

\subsection{Factors consideration for choosing the best system}

In choosing the best system to ensure a successful vertical green facade, few factors should be considered. A larger facade of the building will need a three-dimensional system or the Modular Trellis Panel System since it requires a lot of maintenance and the needs to cover the building in a short length of time. The use of a two-dimensional system in a large building facade will require a constant maintenance since it does not have a specific system to channel the water and nutrients. The length of time for the climbing plant to fully cover the building can take up to 5 to 6 years (Hunter et al. 2014).

In choosing the best system for a vertical garden, the location and size of a building should be taken into account. Considering the fact that the plant will not receive any water supplies in an enclosed space, therefore, a three-dimensional system is more suitable for a green facade located inside of a building. However, both systems can be applied to the facade if it was located outside of the building. 


\subsection{Methodology}

The field measurement is conducted on two buildings with the same orientation and at the same time of the day to ensure they received the same amount of solar heat. The research location was held in Jakarta, Indonesia. To obtain both temperature and humidity data, two buildings that are located at the same location were chosen. A company specializing in vertical gardens, PT. Indonesia Greenwall building will be the location where the humidity and temperature data with the presence of vertical garden is taken while the building without the presence of green facade is represented by the CIMB building located next to it (see Figure 3).

The humidity and temperature of indoor and outdoor of both building are measured hourly from $8.00 \mathrm{am}$ to $5.00 \mathrm{pm}$ using the hygrometer and thermometer respectively. Figure 5 shows the placement of the hygrometer and thermometer in both buildings during the research.

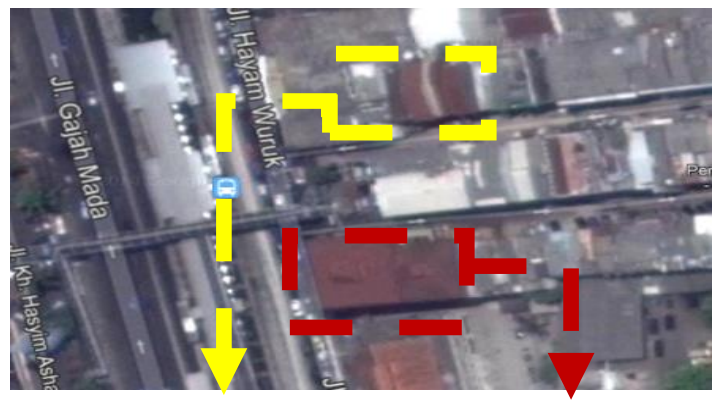

Figure 3: The location of both sample buildings

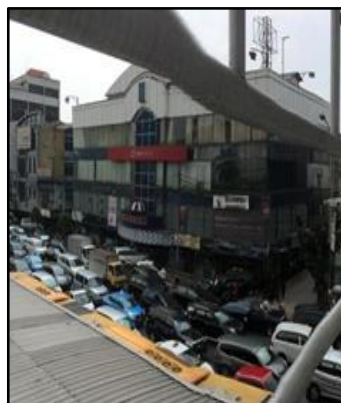

CIMB Bank Building

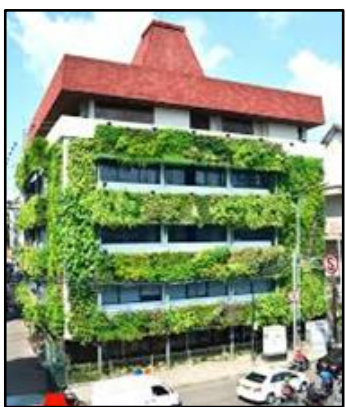

P.T. Indonesia

Figure 4: Panoramic view of both buildings 


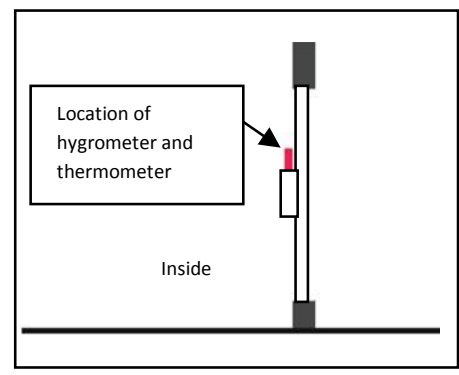

(a) CIMB Bank Building

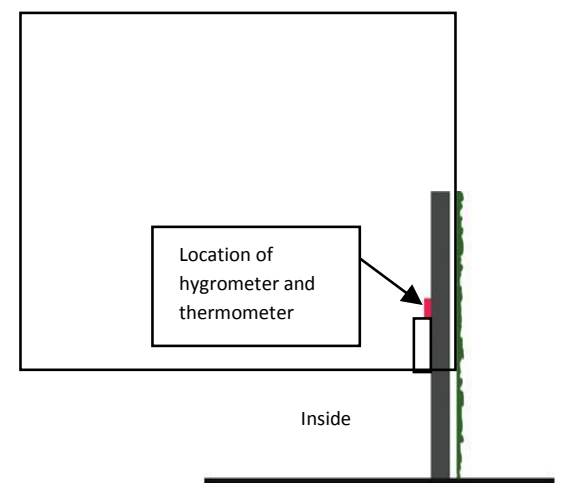

(b) P.T. Indonesia Greenwall Bldg.

Figure 5: Typical section of the sample walls

\section{Results and Discussions}

\subsection{Differences in outdoor and inside temperature of building without the vertical} greening

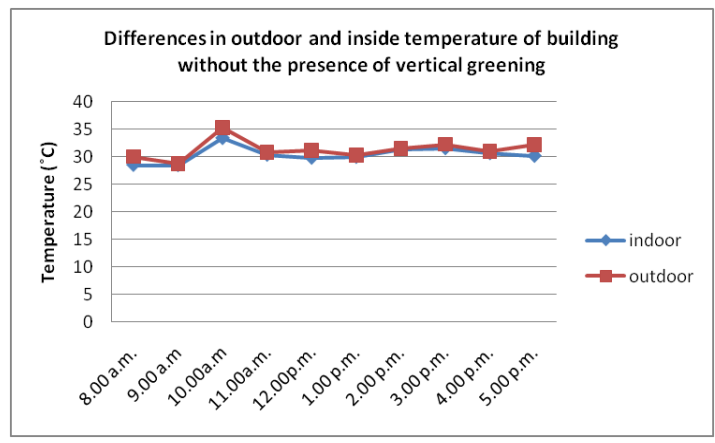

Figure 6: Differences in outdoor and inside temperature ofbuilding without the presence of vertical greening 
Based on the graph in Figure 6, the minimum temperature recorded in both indoor and outdoor of the CIMB building is at 9.00 am with the temperature of $28.5^{\circ} \mathrm{C}$ indoor and $28.7^{\circ} \mathrm{C}$ outside. Subsequently, the maximum temperature recorded was at $10.00 \mathrm{am}$. The maximum temperature inside the building was $33.45^{\circ} \mathrm{C}$ whereas the maximum outside temperature outside the building was $35.3^{\circ} \mathrm{C}$. It can be concluded that the difference between the temperature inside and outside of the building was comparatively low. This was probably due to the low efficiency of the façade used and could not regulate the heat that enters the building.

\subsection{Differences in outdoor and inside temperature of building with vertical greening} The graph in Figure 7 shows that the office building with the presence of vertical greening façade reached its peak temperature of both inside and outside at $3.00 \mathrm{pm}$. The maximum temperature recorded inside the building is $31.1^{\circ} \mathrm{C}$ while the maximum temperature recorded outside the building is $32.75^{\circ} \mathrm{C}$. The minimum temperature recorded is at $9.00 \mathrm{am}$ with the temperature inside the office building is $28.2^{\circ} \mathrm{C}$ and $28.3^{\circ} \mathrm{C}$ for the temperature outside. Due to the rain that occurred at 9.00 am the temperature in both office buildings appeared to have the same minimum temperature.

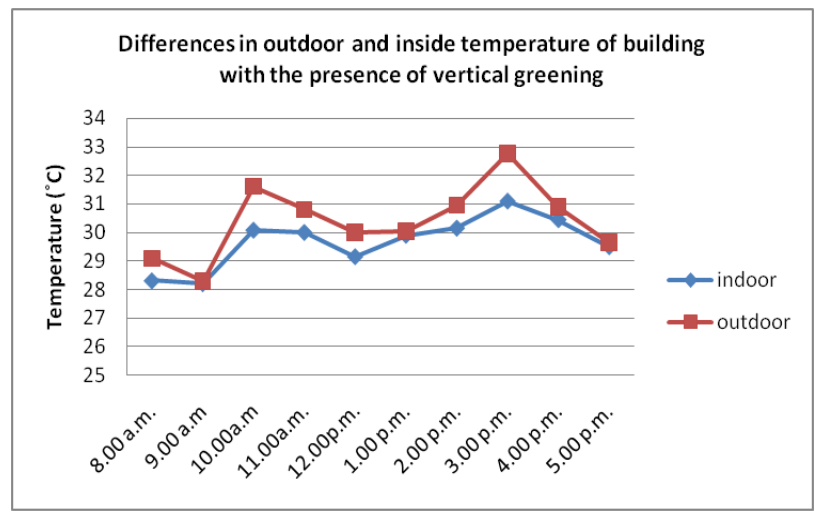

Figure 7:Differences in outdoor and inside temperatur of building with the presence of vertical greening

\subsection{Comparison of temperature percentage reduction in both buildings}

The graph in Figure 8 indicates that the office building with the vertical greening facade clearly has higher amount of temperature reduction compared to the office building without a vertical greening facade. The maximum percentage of temperature recorded at $10.00 \mathrm{am}$ is $0.29 \%$ higher than the temperature in the building without a vertical greening facade. The graph indicates that the highest percentage of temperature reduction in building with vertical garden facade can reach up to $10 \%$ while the minimum percentage it can achieve is 
$0.99 \%$. As for the building without a vertical garden, the maximum percentage of temperature reduction is $6.21 \%$, and the minimum percentage of temperature reduction is $0.97 \%$. Therefore, the facade with the vertical greening is more effective as it can reduce the indoor temperature by $3.79 \%$.

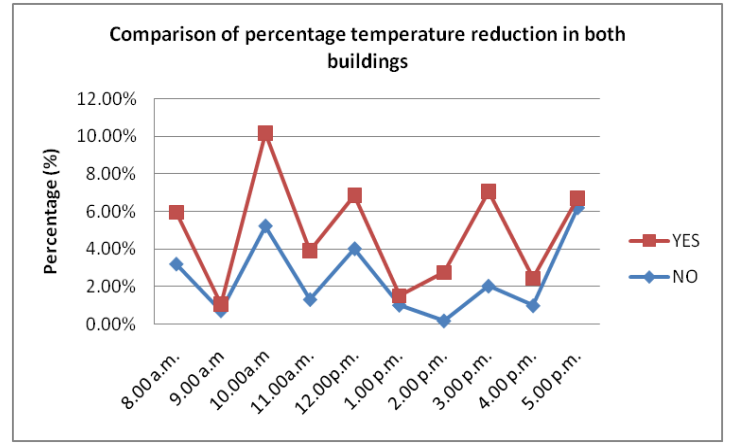

Figure 8: Comparison of temperature reduction in both buildings

\subsection{Differences of indoor temperature in both buildings}

The graph in Figure 9 shows the differences of the indoor temperature of both façades. There were large differences between the two indoor temperatures recorded. The indoor temperature of the building with the green facade is lower than the building without the green facade. From $9.00 \mathrm{am}$ to $10.00 \mathrm{am}$ the graph of the blue line increased dramatically and lost a high amount of temperature after $10.00 \mathrm{am}$. However, the graph of the red line rose slowly and cooled down constantly after $10.00 \mathrm{am}$. Though the indoor temperature of the building without the presence of green facade reduced easily, the temperature of the building with the green facade remained lower.

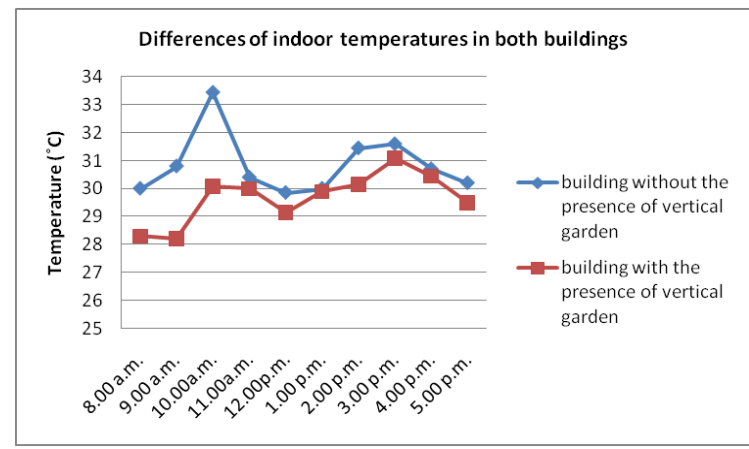

Figure 9: Differences of indoor temperatures in both buildings 


\subsection{Differences of temperature on the outside of both buildings}

The graph in Figure 10 shows that the highest outside temperature recorded for both buildings was at 10.00 am while the minimum outside temperature recorded was at 9.00 am. All in all, there is not much difference between the outside temperatures of both buildings. However, the temperature of the blue line that indicates the building without the vertical greening facade appeared to be higher than the outside temperature of the building with a green facade.

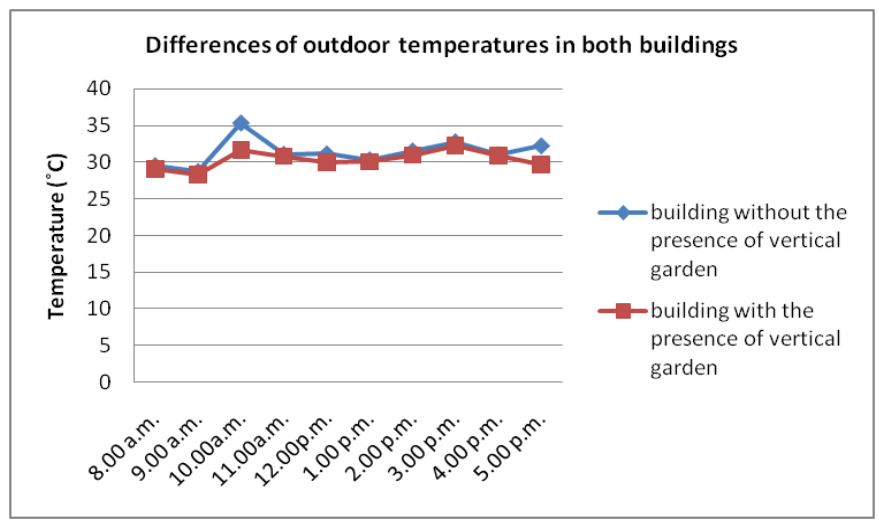

Figure 10: Differences of outdoor temperature in both buildings

\subsection{Comparison of humidity percentages of both buildings}

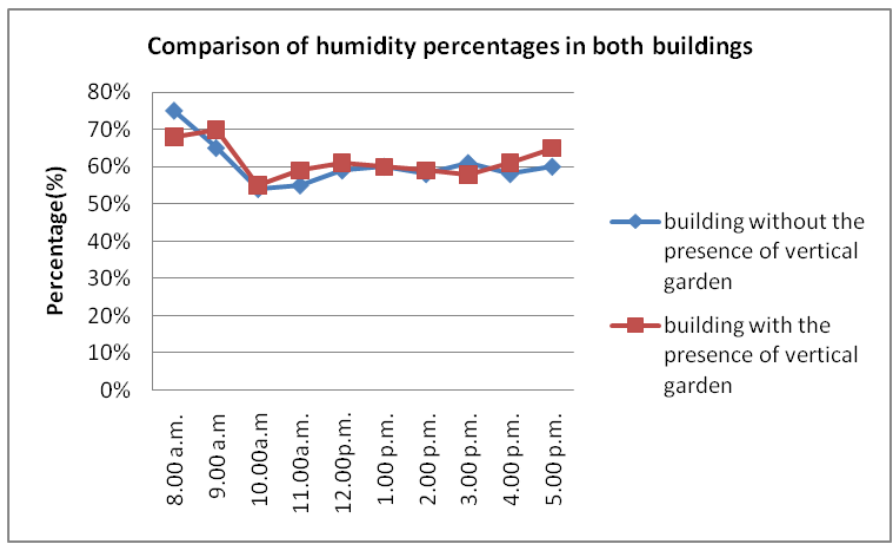

Figure 11: Comparison of humidity percentages in both buildings 
Both data in Figure 11 have a similar pattern starting from $9.00 \mathrm{am}$. Subsequently, both data appears to increase gradually until $12.00 \mathrm{pm}$. After $12.00 \mathrm{pm}$, the graph started to decline slightly until $3.00 \mathrm{pm}$ and rise again. Despite the similar pattern in both buildings data, the percentage of humidity in building with vertical greening facade is relatively lower than the building without the vertical garden.

\subsection{Conclusion}

Based on the data analyzed, the implementation of vertical greening facade on an office building clearly reduces the temperature and humidity of a building. It can be concluded that the building with vertical greening facade has a higher ability to regulate the temperature than the building without the vertical greening facade. However, regarding the ability, the building with green facade (P.T. Indonesia Greenwall) has higher ability to reduce the temperature. The humidity percentage in the building without the presence of vegetation as facade shows a negative result. The percentage of humidity throughout the day is quite high compared to the building with the vertical greening facade. Since the amount of thermal comfort affects the level of thermal comfort of a person, the CIMB Office building shows that the level of thermal comfort is slightly lower compared to the PT. Indonesia Greenwall Office.

Therefore, this study has proved that vertical greening façade do effectively acts as a passive approach towards sustainable building design in the urban area of tropical climate countries. However, the level of effectiveness depends so much on the type of green wall design and the orientation of the façade towards the intense heat of the sun.

\section{Acknowledgement}

The authors would like to thank Universiti Teknologi MARA and the Faculty of Architecture, Planning and Surveying for the infrastructural support.

\section{References}

ASHRAE 55 (2013). Thermal Environmental Conditions for Human Occupancy. Retrieved 15 February 2015.

ASHRAE 62.1 (2013). Ventilation for Acceptable Indoor Air Quality. Retrieved 15 February 2015.

British Standard (2005). BS EN ISO 7730: 2005. Ergonomics of the thermal environment .

Goulding, J. R., Lewis, J. O. and Steemers,T. C. (1992). Energy Conscious Design: A Primer for Architects. London, Batsford for the European Commission, 1992. 
Hunter, A.M. et al. (2014). Quantifying the thermal performance of green facades: A critical review. Ecological Engineering, 63, 102-113.

Kaplan, R. (2013). The role of nature in the context of the workplace. Landscape and Urban Planning, 26(1-4), 193-201.

Krarti M. (2000). Energy audit of building systems: an engineering approach. Boca Raton, FL, CRC Press, 2000.

McMullan, R. (1998). Environmental Science in Building, MacMillian Press Ltd.

Nedhal, A. M. A. T., Syed Fadzil, S. F. and Wan Harun, W. M. (2013). The Effects of Orientation, Ventilation, and Varied WWR on the Thermal Performance of Residential Rooms in the Tropics. Building and Environment, 4(2), 142-149.

Sheweka, S. M. and Mohamed, N. M. (2012). Green Facades as a New Sustainable Approach Towards Climate Change. Energy Procedia, 18, 507-520.

Sunakorn, P. and Yimprayoon, C. (2011). Thermal Performabce of Biofacade with Natural Ventilation in the Tropical Climate. Procedia Engineering, 21, 34-41.

Syed Fadzil, S. F. and Sia Sheau, J. (2004). Sunlight control and daylight distribution analysis: The KOMTAR case study. Building and Environment, 39(6), 713-717.

Wong, N. H. (2010). Thermal evaluation of vertical greenery systems for building walls. Building and Environment, 